\title{
New clade of enigmatic early archosaurs yields insights into early pseudosuchian phylogeny and the biogeography of the archosaur radiation
}

\author{
Richard J Butler ${ }^{1 *}$, Corwin Sullivan², Martín D Ezcurra', Jun Liu², Agustina Lecuona ${ }^{3}$ and Roland B Sookias ${ }^{1}$
}

\begin{abstract}
Background: The origin and early radiation of archosaurs and closely related taxa (Archosauriformes) during the Triassic was a critical event in the evolutionary history of tetrapods. This radiation led to the dinosaur-dominated ecosystems of the Jurassic and Cretaceous, and the high present-day archosaur diversity that includes around 10,000 bird and crocodylian species. The timing and dynamics of this evolutionary radiation are currently obscured by the poorly constrained phylogenetic positions of several key early archosauriform taxa, including several species from the Middle Triassic of Argentina (Gracilisuchus stipanicicorum) and China (Turfanosuchus dabanensis, Yonghesuchus sangbiensis). These species act as unstable 'wildcards' in morphological phylogenetic analyses, reducing phylogenetic resolution.

Results: We present new anatomical data for the type specimens of G. stipanicicorum, T. dabanensis, and $Y$. sangbiensis, and carry out a new morphological phylogenetic analysis of early archosaur relationships. Our results indicate that these three previously enigmatic taxa form a well-supported clade of Middle Triassic archosaurs that we refer to as Gracilisuchidae. Gracilisuchidae is placed basally within Suchia, among the pseudosuchian (crocodile-line) archosaurs. The approximately contemporaneous and morphologically similar G. stipanicicorum and Y. sangbiensis may be sister taxa within Gracilisuchidae.

Conclusions: Our results provide increased resolution of the previously poorly constrained relationships of early archosaurs, with increased levels of phylogenetic support for several key early pseudosuchian clades. Moreover, they falsify previous hypotheses suggesting that $T$. dabanensis and $Y$. sangbiensis are not members of the archosaur crown group. The recognition of Gracilisuchidae provides further support for a rapid phylogenetic diversification of crown archosaurs by the Middle Triassic. The disjunct distribution of the gracilisuchid clade in China and Argentina demonstrates that early archosaurs were distributed over much or all of Pangaea although they may have initially been relatively rare members of faunal assemblages.
\end{abstract}

Keywords: Archosauria, Argentina, Biogeography, China, Gracilisuchidae, Pangaea, Phylogenetics, Suchia, Triassic

\section{Background}

The origin and diversification of archosaurs during the Triassic (252.6-201.3 Ma) was a critical event in the evolutionary history of tetrapods [1-4]. This radiation took place in the aftermath of the Permo-Triassic mass extinction, the largest extinction in the history of life (e.g. [5]), and gave rise to the major clades - dinosaurs, pterosaurs and crocodylomorphs - that dominated a diverse

\footnotetext{
* Correspondence: r.butler.1@bham.ac.uk

${ }^{1}$ School of Geography, Earth and Environmental Sciences, University of Birmingham, Edgbaston, Birmingham B15 2TT, UK

Full list of author information is available at the end of the article
}

range of niches in terrestrial ecosystems for the subsequent 135 million years of the Mesozoic (Jurassic and Cretaceous). Archosaurs remain highly diverse in presentday ecosystems, in the form of around 10,000 living species of birds and crocodylians (e.g. [6]). The radiation of archosaurs and closely related taxa (together forming the clade Archosauriformes) is therefore critical to understanding the origin and evolution of both typical Mesozoic terrestrial vertebrate faunas and the present-day biota. Although new data and analyses have led to substantial recent advances in research into early archosaur phylogenetics and diversity (e.g. [2,3,7]), understanding of the 
radiation remains obscured by the poorly constrained phylogenetic positions of several key early archosauriform taxa.

Among the most enigmatic of these taxa are the smallbodied carnivores Gracilisuchus stipanicicorum, known from multiple relatively complete and well-preserved individuals from the late Middle Triassic of Argentina [8-10], Turfanosuchus dabanensis, known from a single wellpreserved skull and partial postcranial skeleton from the early Middle Triassic of China [11,12], and Yonghesuchus sangbiensis, known from two partial skulls and fragmentary postcranial remains from the late Middle Triassic of China [13]. Gracilisuchus stipanicicorum has been assigned to several phylogenetic positions within the crocodylian stemlineage (Pseudosuchia), including as an ornithosuchid [8], as a sister taxon to phytosaurs [14], or deeply nested within suchian pseudosuchians as a close relative of crocodylomorphs and/or "rauisuchians" [7,15-17]. Similarly, T. dabanensis has been considered a euparkeriid archosauriform [11], an archosauriform close to but outside Archosauria [18], a non-pseudosuchian archosauriform of uncertain affinities [12], a very early pseudosuchian [19], or a "rauisuchiform" pseudosuchian [15], whereas $Y$. sangbiensis has been identified as a non-archosaurian archosauriform [13] that may represent the sister taxon to Archosauria [18]. The most detailed and extensive revision of early archosaur phylogeny recovered both G. stipanicicorum and T. dabanensis close to the base of Suchia [2], but both taxa were highly unstable and acted as phylogenetic 'wildcards', obscuring early pseudosuchian relationships $[2,20]$. Furthermore, this analysis did not include $Y$. sangbiensis. Determining the affinities of all three enigmatic taxa is one of the key challenges remaining in understanding early archosaur phylogeny, and thus in understanding the broader dynamics and palaeobiogeography of this evolutionary radiation.

Here, we provide new anatomical and phylogenetic evidence that G. stipanicicorum, T. dabanensis, and $Y$. sangbiensis form a previously unrecognised Middle Triassic clade of early pseudosuchians that we group together under the family name Gracilisuchidae. Gracilisuchids were among the first archosaur clades to appear in the aftermath of the Permo-Triassic extinction, and achieved a broad palaeogeographic range. This discovery provides critical clarification of the phylogenetic relationships of species involved in the early archosaur radiation.

\section{Institutional abbreviations}

IVPP, Institute of Vertebrate Paleontology and Paleoanthropology, Beijing, China; MCZ, Museum of Comparative Zoology, Harvard University, Cambridge, USA; PULR, Museo de Paleontología, Universidad Nacional de La Rioja, La Rioja, Argentina; PVL, Paleontología de Vertebrados, Instituto Miguel Lillo, Universidad Nacional de Tucumán, Tucumán, Argentina; UFRGS, Instituto de Geociências, Universidade Federal do Rio Grande do Sul, Porto Alegre, Brazil.

\section{Methods}

We added scorings for Yonghesuchus sangbiensis, based upon our original observations of the holotype of this taxon (IVPP V 12378), to the morphological cladistic data set of Nesbitt [2]. We also added a new character to the data set, resulting in a modified data matrix composed of 413 characters and 78 taxa (following the a priori pruning of the following operational taxonomic units [OTUs] that were also excluded by Nesbitt [2]: Archosaurus rossicus, Prestosuchus chiniquensis, UFRGS 0156 T, UFRGS 0152 T, Lewisuchus admixtus and Pseudolagosuchus major). In addition, several scorings for Gracilisuchus stipanicicorum and Turfanosuchus dabanensis were modified based upon new direct observations and interpretations of the relevant specimens. Additional file 1 provides details of and justifications for all rescorings and Additional file 2 is the data matrix. This data matrix is also available at TreeBASE (http:// purl.org/phylo/treebase/phylows/study/TB2:S15917).

The data matrix was analysed under equally weighted parsimony using TNT 1.1 [21]. A heuristic search with 100 replicates of Wagner trees (with random addition sequence) followed by TBR branch-swapping (holding 10 trees per replicate) was performed. The best trees obtained from the replicates were subjected to a final round of TBR branch swapping. Zero length branches in any of the recovered MPTs were collapsed (rule 1 of Coddington \& Scharff [22]). Characters 32, 52, 75, 121, 137, 139, 156, 168, 188, 223, 247, 258, 269, 271, 291, 297, 328, 356 and 399 were treated as additive (ordered) following Nesbitt [2], as was the new character 413. Decay indices (=Bremer support values) were calculated and a bootstrap resampling analysis, using 10,000 pseudoreplicates, was performed reporting both absolute and GC (i.e. difference between the frequencies of recovery in pseudoreplicates of the original group and the most frequently recovered contradictory group) frequencies. Templeton tests (T-t) were conducted using PAUP* 4.0 [23] to determine the significance of alternative phylogenetic topologies, with a $5 \%$ threshold for significance ( $\mathrm{p}$-value $\leq 0.05=$ significantly less parsimonious [S]; p-value $>0.05=$ nonsignificant [NS]).

Nesbitt \& Butler [20] included the enigmatic archosaurs Erpetosuchus granti and Parringtonia gracilis within the data matrix of Nesbitt [2]. They recovered E. granti and $P$. gracilis within a monophyletic Erpetosuchidae; however, this clade acted as a wildcard taxon that substantially reduced phylogenetic consensus within Archosauria. Erpetosuchidae was recovered by Nesbitt \& Butler [20] within a major polytomy that also included Avemetatarsalia, 
Ornithosuchidae, Aetosauria + Revueltosaurus, Ticinosuchus + Paracrocodylomorpha, G. stipanicicorum and T. dabanensis. It is noteworthy that Erpetosuchidae was found as the sister taxon of $T$. dabanensis in some of the most parsimonious trees recovered by Nesbitt \& Butler [20]. As a result, we conducted a second analysis where we added $E$. granti and $P$. gracilis to the data matrix. Character scorings for the two erpetosuchids follow Nesbitt \& Butler [20], with the exception of the scorings for the new character added here. This data matrix was therefore composed of 413 characters and 80 taxa, and was analysed under the same search criteria described above. This modified data matrix is supplied as Additional file 3 , and is also available at TreeBASE as submission S15917 (http://iczn.org/code).

There is some disagreement over the identification and interpretation of the element described as the astragalus of $T$. dabanensis by Wu \& Russell [12], with Nesbitt [2] scoring all astragalus characters as uncertain for $T$. dabanensis. To reflect this uncertainty, we reran both of the analyses described above, but rescored all astragalus characters (characters 354-370) as uncertain for T. dabanensis.

\section{Results}

Review of gracilisuchids: new anatomical information and synapomorphies

\section{Gracilisuchus}

Gracilisuchus stipanicicorum is known from at least six specimens (PULR 08, holotype; MCZ 4116A, 4117, 4118; PVL 4597, 4612) from the Chañares Formation of La Rioja Province, Argentina (Figure 1; [8-10]). Between these six specimens, the majority of the cranial and postcranial osteology of G. stipanicicorum is known. The Chañares Formation is generally considered to be of Ladinian to early Carnian age $[24,25]$. Because the anatomy of $G$. stipanicicorum has recently been comprehensively revised [10], and is in the process of publication by one the authors (AL), we do not provide new detailed descriptive comments here. Nevertheless, we highlight some new observations on the anatomy of G. stipanicicorum below in drawing comparisons to Turfanosuchus dabanensis and Yonghesuchus sangbiensis.

\section{Turfanosuchus}

Turfanosuchus dabanensis is known from a single almost complete skull and partial postcranial skeleton (IVPP V3237) from the Karamayi Formation (=Kelamayi Formation) of Xinjiang Autonomous Region, China (Figure 2; $[11,12])$. The presence of the dicynodont Parakannemeyeria in the Karamayi Formation has been used as evidence for an early Middle Triassic (Anisian) age for this rock unit (e.g. [26]). The Karamayi Formation is considered a lateral equivalent of the Ermaying
Formation of Shanxi Province, which directly underlies the Tongchuan Formation that has yielded Yonghesuchus sangbiensis (see below). Turfanosuchus dabanensis was redescribed in detail by $\mathrm{Wu} \&$ Russell [12] and its phylogenetic position discussed by Nesbitt [2]. Although a nominal second species of Turfanosuchus, "T." shageduensis, has been described [27], the referral of this species to Turfanosuchus has not been upheld by subsequent research $[28,29]$. The diagnosis provided by $\mathrm{Wu}$ \& Russell [12] for $T$. dabanensis requires modification (see below) because the first three characters listed by those authors are also present in $Y$. sangbiensis. Here, we note only a few anatomical features of $T$. dabanensis that supplement the description of Wu \& Russell [12], and we provide further comparisons to $Y$. sangbiensis and G. stipanicicorum below.

Wu \& Russell [12] did not discuss the fact that the ventral end of the squamosal gives rise to a tapering anteroventral process (sensu Nesbitt [2]: character 52) that contacts or nearly contacts the dorsal process of the jugal (Figure 2D: avsq). The distal tip of the anteroventral process approaches the jugal very closely on the left side of the skull, and there is little evidence that the squamosal has been distorted or substantially displaced: the articulation of the left squamosal with the left postorbital appears to be essentially undisturbed. The ventral process of the squamosal on the right side is broken ventrally, and is therefore unnaturally shorter than would have been the case in life. Unfortunately, the quadratojugal is poorly preserved on both sides of the skull, and the nature of its articulation with the squamosal is unclear. However, we suggest that contact, or near contact, between the anteroventral process of the squamosal and the jugal probably subdivided the infratemporal fenestra into upper and lower openings, as also occurs in rauisuchids (Nesbitt [2]: character 52). The upper opening (Figure 2D: uitf) would have been bordered ventrally and posteriorly by the squamosal and anteriorly and dorsally by the ventral and posterior processes of the postorbital. Contact between the squamosal and the jugal is also present in Y. sangbiensis (Figures 3 and 4D; see below) and G. stipanicicorum (Figure 1), but in these taxa there is no upper subdivision of the infratemporal fenestra. Instead, the squamosal and postorbital have a long mutual contact, forming a wide imperforate bar between the infratemporal and supratemporal fenestra. A similar condition is also present in at least some aetosaurs (e.g. [30]). The possibility that the condition in Y. sangbiensis and G. stipanicicorum is homologous to that in $T$. dabanensis is discussed below.

Three osteoderms are present in the type specimen of $T$. dabanensis, rather than one as described by Wu \& Russell [12]. One of the previously undescribed osteoderms has 


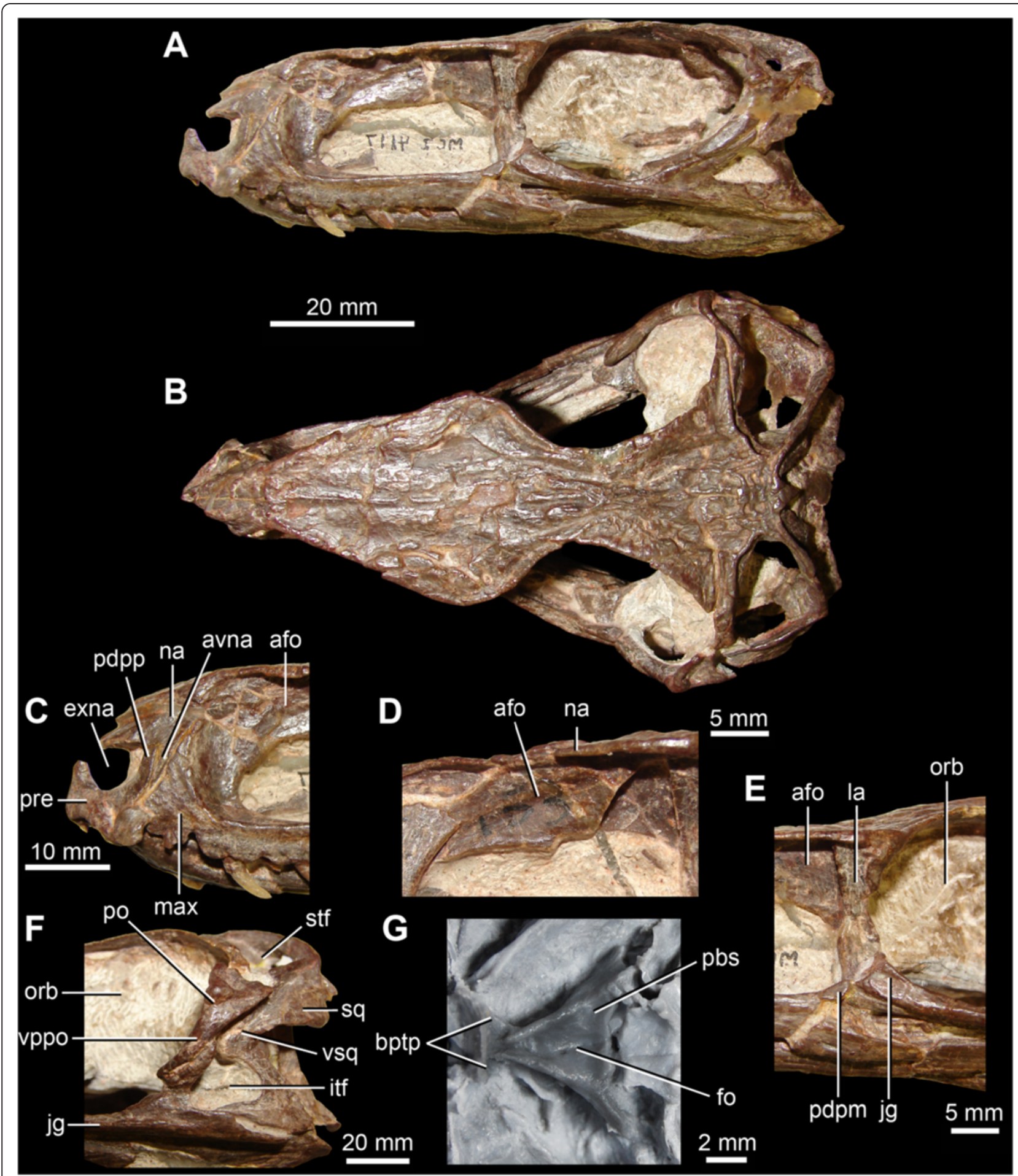

Figure 1 Anatomy of Gracilisuchus stipanicicorum Romer [8]. A. Skull in right lateral view (reversed). B. Skull in dorsal view. C. Close-up of the right premaxilla and anterior ends of right maxilla and nasal in lateral view (reversed). D. Close-up of the left antorbital fossa above the antorbital fenestra in lateral view. E. Posterodorsal process of the posterior end of the right maxilla in lateral view (reversed). F. Left infratemporal region in lateral view. G. Braincase and posterior end of the palate in ventral view. Abbreviations: afo, antorbital fossa; avna, anteroventral process of the nasal; bptp, basipterygoid process; exna, external naris; itf, infratemporal fenestra; jg, jugal; la, lacrimal; max, maxilla; na, nasal; orb, orbit; pbs, parabasisphenoid; pdpm, posterodorsal process of the posterior end of the maxilla; pdpp, posterodorsal process of the premaxilla; po, postorbital; pre, premaxilla; stf, supratemporal fenestra; sq, squamosal; vppo, ventral process of the postorbital; vsq, ventral process of the squamosal. A-F. MCZ 4117. G. cast of PULR 08. 


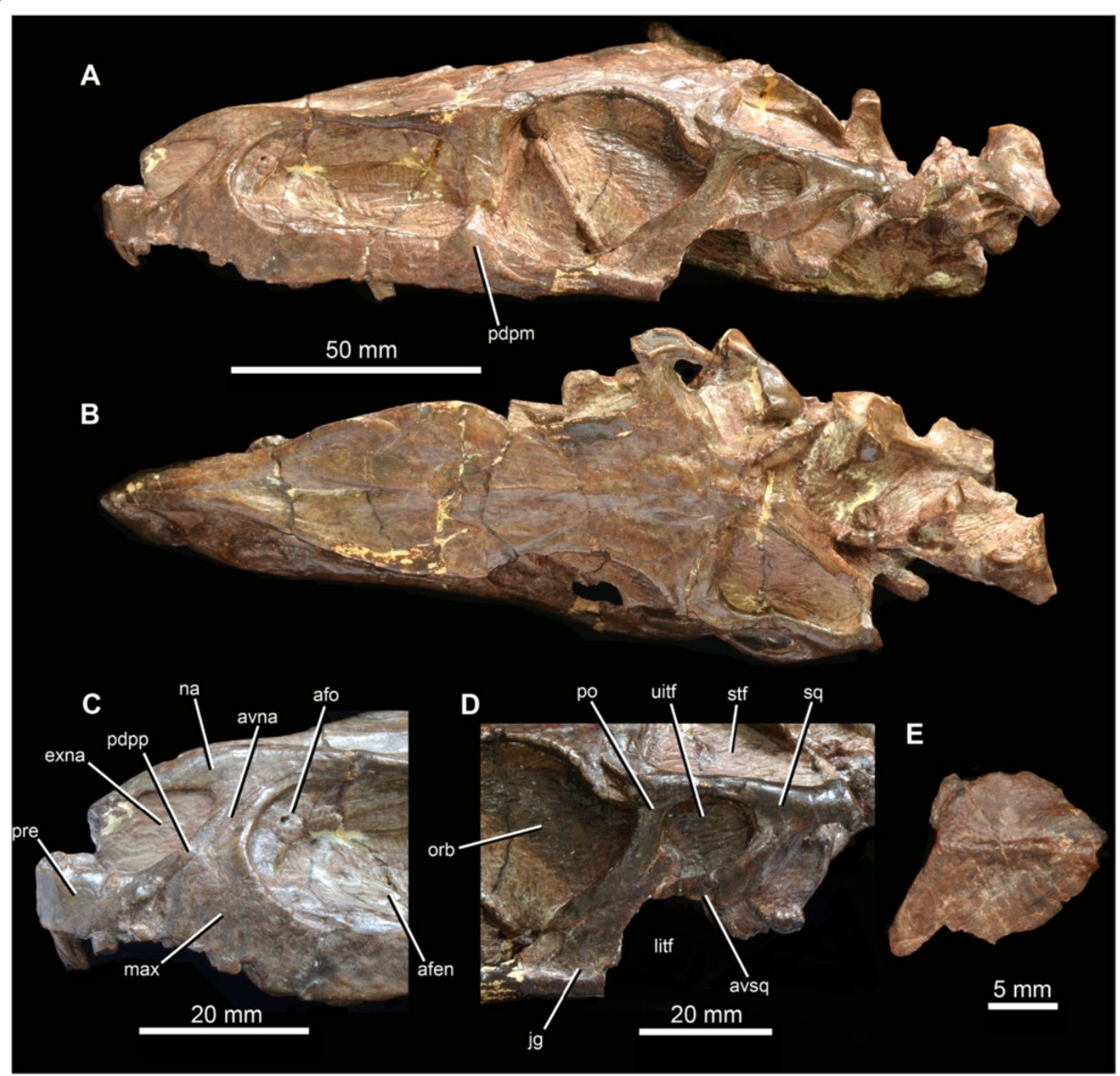

Figure 2 Anatomy of the holotype skull (IVPP V3237) of Turfanosuchus dabanensis Young [11]. A. Skull in left lateral view. B. Skull in dorsal view. C. Close-up of the left premaxilla and anterior ends of left maxilla and nasal in lateral view. D. Left infratemporal region in lateral view. E. Isolated osteoderm in dorsal view. Abbreviations: afen, antorbital fenestra; afo, antorbital fossa; avna, anteroventral process of the nasal; avsq, anteroventral process of the squamosal; exna, external naris; jg, jugal; litf, 'lower' subdivision of the infratemporal fenestra; max, maxilla; na, nasal; orb, orbit; pdpm, posterodorsal process of the posterior end of the maxilla; pdpp, posterodorsal process of the premaxilla; po, postorbital; pre, premaxilla; sq, squamosal; stf, supratemporal fenestra; uitf, 'upper' subdivision of the infratemporal fenestra.

partially intact anterior, posterior and lateral margins (Figure 2E), and these demonstrate that the osteoderms were anteroposteriorly short with an approximately square outline. This osteoderm is anteroposteriorly shorter than individual vertebrae from the same skeleton, suggesting that more than one osteoderm would have been present per vertebra. The osteoderms are slightly asymmetrical, with a longitudinal ridge that is offset (probably laterally) from the midline, and are distinctly ventrally flexed to form an approximate L-shape in transverse section. Similar osteoderms, also with a distinct, laterally offset flexure, are present in G. stipanicicorum (Nesbitt [2]: character 404). Unfortunately, no osteoderms are currently known for $Y$. sangbiensis, but the presence of presacral paramedian osteoderms with a distinct ventral bend near the lateral edge optimises as a synapomorphy of Gracilisuchidae in our phylogenetic analysis. 


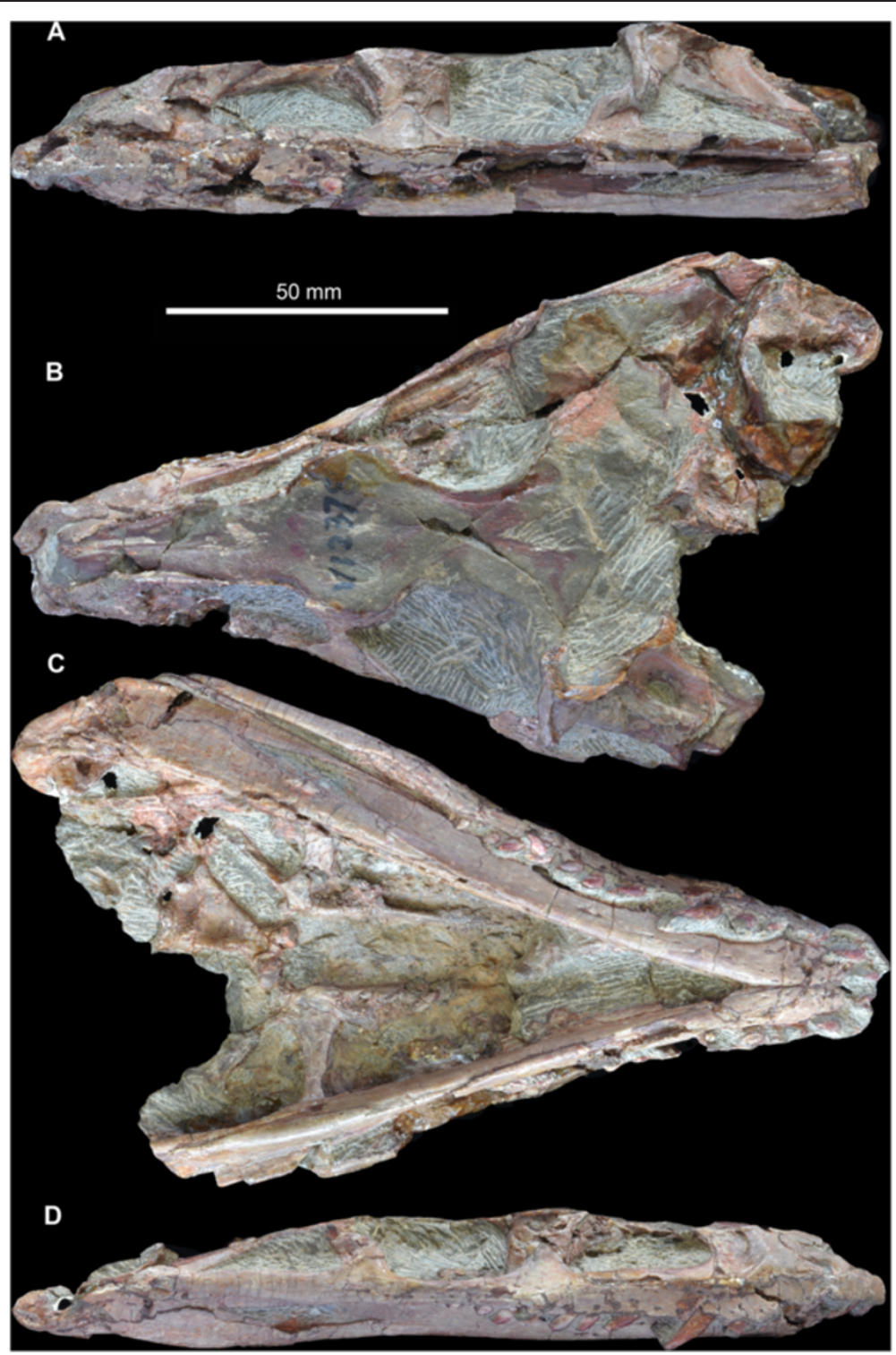

Figure 3 Holotype skull (IVPP V 12378) of Yonghesuchus sangbiensis Wu, Liu \& Li [13]. A. Left lateral view. B. Dorsal view. C. Ventral view. D. Right lateral view.

\section{Yonghesuchus}

Yonghesuchus sangbiensis is known from Member II of the Tongchuan Formation of Shanxi Province, China, on the basis of the incomplete holotype skull (IVPP V 12378; Figures 3 and 4), and a poorly preserved paratype skull with associated cervical vertebrae (IVPP V 12379). Member II of the Tongchuan Formation has been radioisotopically dated at 238.6 $\pm 2.6 \mathrm{Ma}$ and $234.6 \pm 6.5 \mathrm{Ma}$ using SHRIMP U-Pb analyses [31]. This suggests a Ladinian to Carnian age for the Tongchuan Formation, making $Y$. sangbiensis approximately contemporaneous with Gracilisuchus stipanicicorum [24,25].
Yonghesuchus sangbiensis was considered a nonarchosaurian archosauriform by Wu et al. [13] and recovered as the sister taxon of Archosauria by Dilkes \& Sues [18]. The non-archosaurian position of $Y$. sangbiensis in these previous studies was based upon the retention of palatal teeth on the palatal ramus of the pterygoid, given that absence of palatal teeth is the nearly universal condition in crown archosaurs and optimises as a synapomorphy of Archosauria + Phytosauria in the analysis of Nesbitt [2]. However, as discussed by Nesbitt [2], teeth are present on the palatal ramus of the pterygoid in several early dinosauriforms (e.g. Lewisuchus 


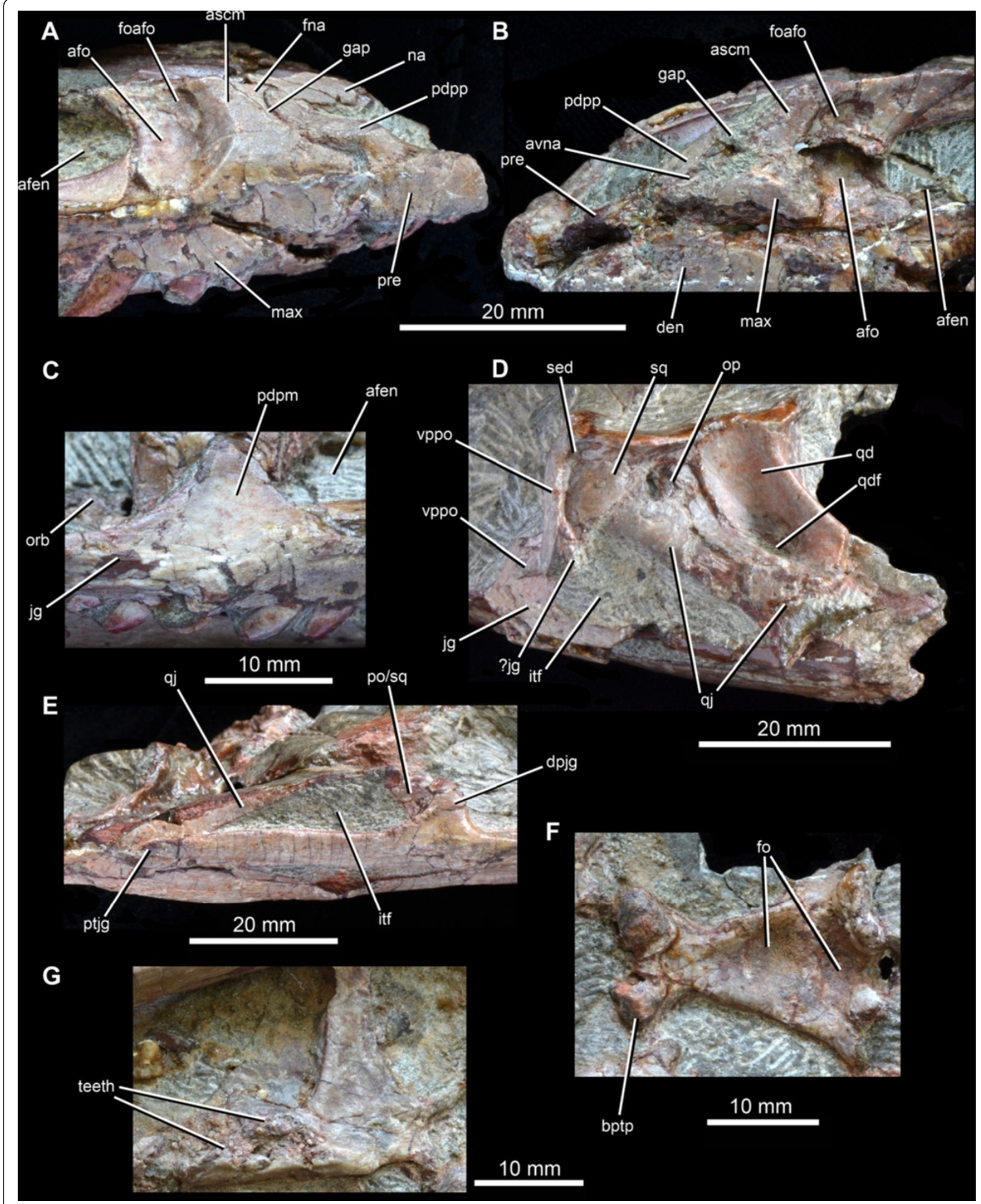

Figure 4 (See legend on next page.) 
(See figure on previous page.)

Figure 4 Anatomy of the holotype skull (IVPP V 12378) of Yonghesuchus sangbiensis Wu, Liu \& Li [13]. A. Close-up of the right premaxilla and anterior end of right maxilla in lateral view. B. Close-up of the left premaxilla and anterior end of left maxilla in lateral view. C. Posterodorsal process of the posterior end of the right maxilla in lateral view. D. Left infratemporal region in lateral view. E. Right infratemporal region in lateral view. F. Parabasisphenoid in ventral view. G. Left pterygoid in ventral view. Abbreviations: afen, antorbital fenestra; afo, antorbital fossa; ascm, ascending process of the maxilla; avna, anteroventral process of the nasal; bptp, basipterygoid process; den, dentary; dpjg, dorsal process of the jugal; en, dentary; fna, facet for the nasal; fo, fossae; foafo, accessory fossa within antorbital fossa; gap, gap between the posterodorsal process of the maxilla and the anterior margin of the maxilla into which the anteroventral process of the nasal would have fitted; itf, infratemporal fenestra; jg, jugal; max, maxilla; na, nasal; op, opening between the squamosal, quadrate and quadratojugal; orb, orbit; pdpm, posterodorsal process of the posterior end of the maxilla; pdpp, posterodorsal process of the premaxilla; po/sq, fragments of the postorbital and/or squamosal; pre, premaxilla; ptjg, posterior termination of the jugal; qd, quadrate; qdf, quadrate foramen; qj, quadratojugal; sed, sediment marking a small gap between the postorbital and the squamosal; sq, squamosal; vppo, ventral process of the postorbital.

admixtus: PULR 01; Eoraptor lunensis: [32]; Eodromaeus murphi: [33]) and in Turfanosuchus dabanensis, which was well supported as a pseudosuchian archosaur by his phylogenetic analysis. Thus the evidence that $Y$. sangbiensis falls outside the crown group is weak.

The holotype skull of $Y$. sangbiensis (IVPP V 12378) has been crushed dorsoventrally (Figure 3), most of the skull roof has been eroded away, and many of the remaining bone surfaces are fractured or poorly preserved. As a result, interpretation of several areas of the skull is problematic. The original description of $Y$. sangbiensis by Wu et al. [13] was accurate in most respects, and those authors correctly documented several autapomorphic features that support the validity of the species. However, one of the autapomorphies that they identified (their autapomorphy 4: "posterior two thirds of descending process of postorbital broadly and deeply concave") is considered here to reflect a misinterpretation of the temporal region of the skull. We here reinterpret several anatomical features of $Y$. sangbiensis and note other features shared with $T$. dabanensis and/or G. stipanicicorum.

On the right side of IVPP V 12378 (in which the premaxillary region is better preserved), there is a small gap, walled medially by a recessed area of bone, which separates the posterior margin of the tip of the posterodorsal process (= "postnarial process", "maxillary process" or "subnarial process") of the premaxilla from the anterior margin of the dorsal or ascending process of the maxilla (Figure 4A: gap). This gap may have been broader originally, as dorsal and posterior rotation of the premaxilla has evidently occurred post-mortem. This gap appears to be walled medially by a narrow anterior extension of the maxilla. On the left side of the skull the posterodorsal process of the premaxilla is poorly preserved, but there is a similar narrow gap between the posterodorsal process of the premaxilla and the anterior edge of the ascending process of the maxilla (Figure 4B). The ventral part of the gap contains an anteroventrally-tapering fragment of bone that likely represents the ventral tip of an anteroventral process of the nasal (Figure 4B: avna), suggesting that the gap is an articular area that accommodates this process. The nature of the articulation between the nasal and the posterodorsal process of the premaxilla in $Y$. sangbiensis would then be very similar to the condition in $T$. dabanensis (Figure 2C; [12]; [2]: character 4) and G. stipanicicorum (Figure 1; MCZ 4117; contra [8]) in which the nasal forms a slot to accommodate the posterodorsal process of the premaxilla and a narrow, triangular anteroventral process posterior to the slot to separate the premaxilla from the maxilla. Although the slot in the nasal is not clearly preserved in $Y$. sangbiensis, the similarities documented above lead us to score this taxon as for T. dabanensis and G. stipanicicorum for character 4 of the phylogenetic analysis, and this character state is here identified as a synapomorphy of Gracilisuchidae.

The maxilla of $Y$. sangbiensis bears a well-developed antorbital fossa that extends onto the horizontal process (= "posterior process", or "main body") of the maxilla below the antorbital fenestra, and continues along nearly the entire ventral margin of the fenestra. The presence of an antorbital fossa that extends onto the horizontal process was identified as a synapomorphy of crown Archosauria by Nesbitt [2], and is also present in $T$. dabanensis and G. stipanicicorum. Unfortunately, the palatal processes of the maxillae are not exposed in $Y$. sangbiensis, so it cannot be confirmed whether or not they contact one another along the midline as in crown archosaurs [2].

As noted by Wu et al. [13], the maxilla of $Y$. sangbiensis has a pronounced "posterodorsal process" at the posterior end of the horizontal process, posterior to the antorbital fenestra and fossa (Figure 4C: pdpm). This posterodorsal process forms a dorsoventrally deep, symmetrical, triangular projection with anterodorsal and posterodorsal margins that form steep angles to the horizontal. The process extends dorsal to the dorsal margin of the horizontal process by a distance that is almost equivalent to the height of the horizontal process of the maxilla immediately anterior to the posterodorsal process. Moreover, this process contacts the lacrimal and excludes the short anterior process of the jugal from forming part of the margin of the antorbital fenestra. A similarly well-developed process is present in T. dabanensis (Figure 2A), but in most archosauriforms the maxilla either tapers or maintains 
a nearly constant depth towards its posterior end [2]. Gracilisuchus stipanicicorum also has a posterodorsal process of the maxilla (Figure 1; PULR 08, PVL 4597, MCZ 4116; contra [8]). This process rises as a symmetrical triangular projection, but the anterodorsal and posterodorsal margins form less steep angles to the horizontal. Moreover, the relative height of the projection is less than in $T$. dabanensis or $Y$. sangbiensis. As such, the condition in G. stipanicicorum appears to be intermediate between the primitive archosauriform condition and that present in Y. sangbiensis and T. dabanensis. A similar condition to that of G. stipanicicorum also occurs in some, but not all, aetosaurs (e.g. [30]). The presence of a posterodorsal process of the maxilla optimises here as a synapomorphy of Gracilisuchidae.

The skull roof of IVPP V 12378 is mostly missing, but much of its outline can be reconstructed on the basis of preserved traces of bone around the margins and impressions of the ventral surfaces of some midline bones (Figure 3B). Anterior to the orbits the skull table is strongly expanded transversely at the level of the prefrontals (maximum transverse width of $30 \mathrm{~mm}$ as opposed to $17 \mathrm{~mm}$ across the orbits), similar to the condition in $T$. dabanensis and G. stipanicicorum (MCZ 4117), as well as in some other pseudosuchians such as ornithosuchids [34]. The skull roof tapers in transverse width anterior to this point in IVPP V 12378. It seems likely that the nasal would have formed the dorsal border of the antorbital fossa, as also occurs in T. dabanensis, G. stipanicicorum (e.g. MCZ 4117), Aetosaurus ferratus and several loricatan pseudosuchians and saurischian dinosaurs ([2]: character 37). Formation of the dorsal border of the antorbital fossa by the nasal optimises here as a synapomorphy of Gracilisuchidae convergently acquired in the other taxa in which it occurs [2]. Further anteriorly, dorsal to the maxillary dorsal or ascending process, the skull roof impressions suggest that the lateral margins of the nasals were thickened into ridges in $Y$. sangbiensis, as also occurs in the equivalent region in $T$. dabanensis and G. stipanicicorum (e.g. MCZ 4117). Unfortunately, no information is available on the outline of the frontals in $Y$. sangbiensis; however, anteriorly tapering frontals ([2]: character 43) optimise here as a synapomorphy of Gracilisuchidae, being present in both T. dabanensis [12] and G. stipanicicorum ([10]; contra $[2,8])$.

Examination of the infratemporal region of $Y$. sangbiensis (Figure 4D, E) in the light of comparisons to G. stipanicicorum suggests a somewhat different interpretation than that presented by Wu et al. [13] in the original description. The dorsal part of the posterior skull of IVPP V 12378 has been eroded away, complicating interpretation. On the left side of IVPP V 12378, the jugalpostorbital bar is preserved, but has been broken at about midheight and dorsoventrally compressed. The very tip of the ventral process of the postorbital apparently overlies the lateral surface of the jugal. A fragment of the tip of the dorsal process of the jugal that has broken away from the rest of the bone may be present posterior to the ventral termination of the postorbital (Figure 4D: ?jg).

The postorbital is incomplete dorsally, and in fact little of this bone is preserved other than the anteroposteriorly narrow ventral process and the base of the anterodorsal process. The posterior (or squamosal) process is not preserved. Immediately posterior to the dorsal two thirds of the ventral process of the postorbital, there is a broad, medially recessed area of bone that Wu et al. [13] interpreted as a fossa on the ventral process of the postorbital. However, in posterolateral view a thin line of sediment separates this recessed area from the ventral process of the postorbital (Figure 4D: sed). We interpret this recessed area of bone instead as the tip of the anterior process of the squamosal, which in G. stipanicicorum extends anteroventrally to contact the dorsal tip of the dorsal process of the jugal (e.g. PULR 08, MCZ 4117; Figure 1). This recessed area in IVPP V 12378 expands in anteroposterior width towards its dorsal preserved margin, where it is overhung by a ridge; a similar ridge on the squamosal that overhangs the tip of the anterior process is present in G. stipanicicorum (e.g. MCZ 4117; Figure 1).

The anteroventral tip of the squamosal of IVPP V 12378 is contacted posteriorly by the quadratojugal (Figure 4D). The dorsal process of the quadratojugal is directed anterodorsally in lateral view as in G. stipanicicorum; this does not appear to be a result of distortion. The dorsal process encloses together with the jugal and the squamosal a small lower infratemporal fenestra that has a triangular outline (Figure 4D: litf), being dorsoventrally deepest at its anterior end and sharply tapering posteriorly. The dorsal process of the left quadratojugal is damaged and part of it appears to have been slightly medially displaced, as can be inferred from a preserved impression of its original position. The quadratojugal clearly contacts the quadrate ventral to the quadrate foramen, but it is less clear whether or not there is also contact dorsal to the foramen. In the area dorsal to the quadrate foramen there is an apparent gap filled with sediment (the surface coloration of which is difficult to distinguish from that of the surrounding bone) between the anterior process of the squamosal, the quadrate, and the quadratojugal (Figure 4D: op). Whether the opening surrounded by these bones is a genuine morphological feature, or merely the result of damage to the quadrate and/or quadratojugal, cannot be determined with certainty. However, a large and apparently equivalent opening between the squamosal, quadrate and quadratojugal is present in G. stipanicicorum (e.g. PULR 08, MCZ 4118).

The dorsal process of the right quadratojugal of IVPP V 12378 is similarly anterodorsally orientated (Figure 4E), but only its anteroventral edge is preserved. Anteriorly, 
the incomplete dorsal process of the jugal is contacted medially and posteriorly by some damaged fragments of bone that likely represent parts of the postorbital and squamosal. The quadratojugal also contacts these fragments, closing the small, ventrally placed infratemporal fenestra. The quadrate of IVPP V 12378 has a large quadrate foramen and a very strong ridge separating the lateral and pterygoid wings (Figure 4D).

Our reinterpretation of the temporal region of $Y$. sangbiensis reveals an unusual arrangement that is very similar to that in G. stipanicicorum in several respects. The squamosal forms a ventrally expanded contact with the postorbital and a more limited contact with the jugal, restricting the infratemporal fenestra to the ventral part of the lateral surface of the skull. Yonghesuchus sangbiensis also shares with G. stipanicicorum a strong ridge on the squamosal, an anterodorsally directed dorsal process of the quadratojugal, and potentially an additional opening between the squamosal, quadratojugal and quadrate. The similarities are partially captured by state 1 of character 66 of our phylogenetic analysis ("postorbital-squamosal contact continues ventrally for much or most of the ventral length of the squamosal"), which supports a sister grouping between $Y$. sangbiensis and G. stipanicicorum. Although the temporal region of $T$. dabanensis shows similarities to $Y$. sangbiensis and G. stipanicicorum such as a squamosaljugal contact, or near contact, it also shows important differences, most notably in the probable presence of a dorsally placed opening between the squamosal and postorbital that is clearly absent in the latter two taxa. For this reason, a primary homology between the relationship of the anterior process of the squamosal to the postorbital and jugal in $T$. dabanensis versus $Y$. sangbiensis and G. stipanicicorum is not currently included within our phylogenetic analysis; thus $T$. dabanensis is scored as state 0 for character 66 in our analysis. However, the possibility of primary homology deserves further consideration as better preserved material is discovered.

Yonghesuchus sangbiensis also shows two additional noteworthy similarities to G. stipanicicorum that optimise as synapomorphies of a $Y$. sangbiensis + G. stipanicicorum clade. First, both possess a jugal that extends posteriorly beyond the level of the posterior border of the infratemporal fenestra ([2]: character 72; Figures 1 and $4 \mathrm{E}$ ), whereas $T$. dabanensis appears to retain a plesiomorphic, proportionately shorter posterior process of the jugal, although confirmation of this character is complicated by poor preservation of this region [12]. Second, the parabasisphenoid of $Y$. sangbiensis (Figure $4 \mathrm{~F}$ ) is very similar to that of G. stipanicicorum (MCZ 4117; Figure 1) in being strongly elongated anteroposteriorly between the basal tubera and basipterygoid processes such that it is more than 1.5 times as long as wide ([2]: character 103). Similar elongation is not present in T. dabanensis [12].
Moreover, in both $Y$. sangbiensis and G. stipanicicorum the foramina for the internal carotid arteries are not visible in ventral view and must have entered the braincase laterally (possible synapomorphy of Archosauria following Nesbitt [2] and plesiomorphic for Gracilisuchidae), unlike in T. dabanensis [12].

In general, as preserved, the skull of $Y$. sangbiensis appears to be extremely similar to that of G. stipanicicorum. One major difference is the retention of palatal teeth on the pterygoid of $Y$. sangbiensis (Figure 4G), in contrast to the complete absence of palatal teeth in G. stipanicicorum [10]. The skulls of both $Y$. sangbiensis and $G$. stipanicicorum show important similarities to that of $T$. dabanensis, but $T$. dabanensis lacks some of the specialisations seen in the former two species.

\section{Phylogenetic analyses}

The search recovered 90 most parsimonious trees of 1313 steps, with a consistency index $(\mathrm{CI})$ of 0.3679 , a retention index (RI) of 0.7706, and the best score hit in all the replications. The topology of the strict consensus tree (Figure 5; Additional file 4) is almost identical to that originally obtained by Nesbitt [2], differing only in that phylogenetic interrelationships among early suchians are completely resolved. Nesbitt [2] recovered a polytomy among Gracilisuchus stipanicicorum, Turfanosuchus dabanensis, Revueltosaurus callenderi + Aetosauria, and Ticinosuchus ferox + Paracrocodylomorpha. By contrast, in the present analysis the clade composed of $R$. callenderi + Aetosauria was recovered at the base of Suchia, and a novel clade formed by $G$. stipanicicorum, $T$. dabanensis and $Y$. sangbiensis was recovered as the sister-taxon of T. ferox + Paracrocodylomorpha. This novel clade is termed here Gracilisuchidae (see Systematic Palaeontology, below). The monophyly of Gracilisuchidae is supported by six unambiguous synapomorphies (see Diagnosis in the Systematic Palaeontology section, below). Within Gracilisuchidae, G. stipanicicorum was recovered as more closely related to $Y$. sangbiensis than to $T$. dabanensis on the basis of the following three synapomorphies: (1) postorbital-squamosal contact continues ventrally for much or most of the ventral length of the squamosal (character 66: $0 \rightarrow 1$ ); (2) jugal with a posterior termination posterior to the infratemporal fenestra (character 72: $0 \rightarrow 1$ ); (3) parabasisphenoid between basal tubera and basipterygoid processes significantly elongated, at least 1.5 times longer than wide (character 103: $0 \rightarrow 1$ ).

Gracilisuchidae is relatively strongly supported, with a Bremer support of 4 and absolute and GC bootstrap frequencies of $66 \%$ and $55 \%$, respectively (see Additional file 4). By contrast, the recovered pattern of relationships within Gracilisuchidae is considerably less well supported, the $Y$. sangbiensis $+G$. stipanicicorum clade having a Bremer support of 1 and bootstrap frequencies below $50 \%$. The Bremer support value for Gracilisuchidae remains 


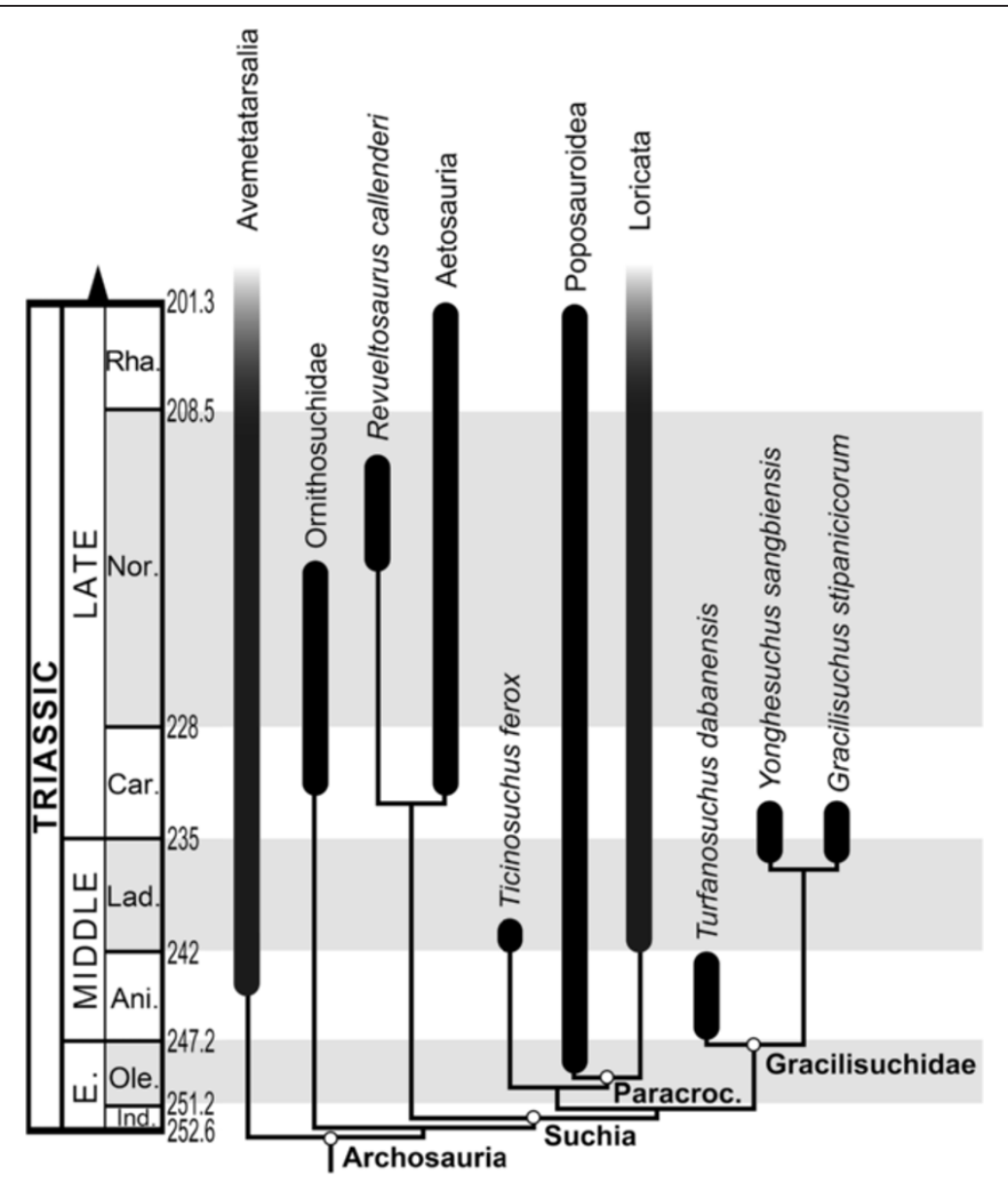

Figure 5 Simplified version of the strict consensus of $\mathbf{9 0}$ most parsimonious trees. Figure shows known stratigraphic ranges for major clades and stratigraphic uncertainty for gracilisuchid taxa, which are all known from point occurences.

unchanged following the a posteriori exclusion of either $Y$. sangbiensis or T. dabanensis. However, resampling values for the G. stipanicicorum $+Y$. sangbiensis clade increase significantly after the a posteriori exclusion of $T$. dabanensis, with new absolute and GC frequencies of $75 \%$ (difference $=+32 \%$ ) and $61 \%$ (difference $=+42 \%$ ) respectively.

The full resolution of relationships among early members of Suchia in the current analysis results in increased Bremer support values for several clades within Pseudosuchia, compared to those obtained in the original analysis of Nesbitt [2]. The clades affected are Ornithosuchidae (support increases from 8 to 13), Suchia (from 1 to 3), the R. callenderi + Aetosauria clade (from 9 to 10), Aetosauria (from 10 to 14), and the T. ferox + Paracrocodylomorpha clade (from 1 to 4). Accordingly, the results of the present analysis are consistent with those of Nesbitt [2] but provide increased support for several clades that lie close to the base of Pseudosuchia.

Analysis of suboptimal topologies shows that 10 additional steps are needed to find $Y$. sangbiensis as the sister-taxon of phytosaurs and archosaurs (relationship found by Dilkes \& Sues [18]; T-t p-value $=0.0129$ [S]), 13 extra steps to position $T$. dabanensis as the most basal pseudosuchian (relationship found by Ezcurra et al. [19]; T-t p-value $=0.0010[S]$ ) and 28 additional steps to position G. stipanicicorum as the most basal crocodylomorph (relationship found by several previous authors: e.g. Benton \& Walker [17]; T-t p-value $=0.0002$ [S]). However, only one additional step is necessary to recover a sistertaxon relationship between the Chinese taxa T. dabanensis and $Y$. sangbiensis (T-t p-value $=1.000[\mathrm{NS}]$ ), and only three additional steps to find G. stipanicicorum more closely related to $T$. dabanensis than to $Y$. sangbiensis (T-t $\mathrm{p}$-value $=0.2500[\mathrm{NS}]$ ). In addition, only three additional steps are necessary to find a monophyletic Gracilisuchidae as the sister-taxon of $R$. callenderi + Aetosauria, and this hypothesis was not rejected by a Templeton test (T-t $\mathrm{p}$-value $=0.3750[\mathrm{NS}])$.

The analysis including erpetosuchids recovered 630 most parsimonious trees of 1330 steps, with a consistency index (CI) of 0.3632, a retention index (RI) of 0.7677 , and the best score hit in $99 \%$ of replications. The topology of 
the strict consensus tree (Additional file 5) closely resembles that recovered by Nesbitt \& Butler [20], being poorly resolved with a major polytomy at the base of Archosauria. Gracilisuchidae is recovered as monophyletic, with a Bremer support of 3 and absolute and GC bootstrap frequencies of $62 \%$ and 52\%, respectively. Erpetosuchidae was found as the sister-taxon of Gracilisuchidae in some (but not all) of the most parsimonious trees, and this clade was recovered as the sister-taxon of $T$. ferox + Paracrocodylomorpha. The internal relationships among gracilisuchids are not resolved in this analysis.

Rescoring the astragalus characters as uncertain ("?") for $T$. dabanensis did not substantially affect our results. Rerunning the main analysis (that excluding erpetosuchids) yielded 90 most parsimonious trees of 1311 steps, with the strict consensus tree showing the same topology and similar support metrics as the original analysis (Additional file 6). Rerunning the analysis that included erpetosuchids yielded 630 most parsimonious trees of 1328 steps, with the strict consensus tree showing the same topology and similar support metrics as the original analysis (Additional file 7).

\section{Systematic palaeontology}

Archosauria Cope [35] sensu Sereno [36]

Pseudosuchia Zittel [37] sensu Nesbitt [2]

Suchia Krebs [38] sensu Nesbitt [2]

Gracilisuchidae new family

\section{Included taxa}

Gracilisuchus stipanicicorum Romer [8]

Turfanosuchus dabanensis Young [11], and

Yonghesuchus sangbiensis Wu et al. [13].

\section{Phylogenetic definition}

The most inclusive clade containing Gracilisuchus stipanicicorum Romer [8], but not Ornithosuchus longidens (Huxley) [39], Aetosaurus ferratus Fraas [40], Poposaurus gracilis Mehl [41], Postosuchus kirkpatricki Chatterjee [42], Rutiodon carolinensis (Emmons) [43], Erpetosuchus granti Newton [44], Revueltosaurus callenderi Hunt [45], Crocodylus niloticus (Laurenti) [46], or Passer domesticus Linnaeus [47] (new definition).

\section{Diagnosis}

Diagnosed by the following unambiguous synapomorphies (character number in the phylogenetic analysis and reconstructed state transformation in brackets): (1) premaxilla with posterodorsal process (= "postnarial process", "maxillary process" or "subnarial process") that fits into slot on lateral surface of nasal (character $4: 0 \rightarrow 3$ ); (2) nasal forms part of dorsal border of antorbital fossa (character 37: $0 \rightarrow 1$ ); (3) frontal with anterior portion that tapers anteriorly along midline (character $43: 0 \rightarrow 1$ ); (4) calcaneum with dorsoventrally aligned median depression on distal end of tuber (character 375: $0 \rightarrow 1$ ); (5) presacral paramedian osteoderms with distinct longitudinal bend near lateral edge (character 404: $0 \rightarrow 1$ ); (6) maxilla with triangular posterodorsal process possessing clear dorsal apex and formed by discrete expansion of posterior end of horizontal process of maxilla (character 413: $0 \rightarrow 1 / 2$ ).

\section{Stratigraphic and geographic distribution}

Known from the early Middle Triassic (Anisian) of Xinjiang, China (Turfanosuchus dabanensis), and the late Middle Triassic-early Late Triassic (Ladinian-early Carnian) of Shanxi, China (Yonghesuchus sangbiensis) and La Rioja Province, Argentina (Gracilisuchus stipanicicorum). The known record of gracilisuchids therefore spans the Middle Triassic and has a disjunct palaeogeographic distribution.

\section{Remarks}

Carroll [48] listed the family Gracilisuchidae as part of a classification scheme for all fossil vertebrates, but without discussion or justification. In addition to Gracilisuchus stipanicicorum, Carroll [48] assigned to Gracilisuchidae the Middle Triassic taxon Lewisuchus admixtus, which is now considered a probable silesaurid dinosauriform [2,49]. Carroll did not provide a description or definition for Gracilisuchidae, and as such it is unavailable under Article 13.1.1 of the International Code on Zoological Nomenclature (http://iczn.org/iczn). We here provide the first valid diagnosis of Gracilisuchidae, including three genera and species, for which we provide a novel phylogenetic definition.

\section{Gracilisuchus stipanicicorum Romer [8].}

\section{Holotype}

PULR 08, partially articulated skull and mandible, and partial postcranium.

\section{Referred material}

MCZ 4116A, 4117, 4118, PVL 4597, 4612 (for details see Lecuona \& Desojo [11]).

\section{Diagnosis}

Diagnosed by the following unique combination of characters (autapomorphies marked with an asterisk): large antorbital fenestra occupying approximately $30 \%$ of anteroposterior length of skull table (measured from anterior end of premaxilla to posterior end of parietals); large antorbital fossa occupying $40 \%$ of length of skull table; presence of postfrontal and small postparietal; anterior ramus of squamosal laterally expanded; interparietal suture partially obliterated; narrow occipital portion of parietals; postzygapophyseal facet of axis horizontal, posteriorly directed, and facing ventrally*; high and vertical 
anterior border of axial neural spine*; presence of a ventral longitudinal median keel on axial centrum; poor development of ventral keel on cervical vertebrae; circular depression on the mid-dorsal region of the neural arch of cervical vertebrae; spine table in posterior cervical vertebrae; lack of well-defined acetabular surface on pubis; L-shaped lamina on proximal pubic apron; ischiadic symphysis proximally located; femur longer than tibia; knob-shaped iliofibular trochanter; two paramedian osteoderms per vertebra [11].

\section{Type locality}

Three kilometres north of the northern branch of the Chañares River and $5 \mathrm{~km}$ southwest of the Puerta de Talampaya, La Rioja Province, Argentina.

\section{Type horizon}

Chañares Formation. Late Middle-early Late Triassic: Ladinian-Carnian $[24,25]$.

Turfanosuchus dabanensis Young [11].

\section{Holotype}

IVPP V3237, fairly complete skull and partial postcranium.

\section{Diagnosis}

Characterised by the following autapomorphies: (1) dorsal or postorbital process of jugal with lateral surface strongly inset relative to lateral surface of remainder of bone, and with very broad ventral base; (2) angular excluded by surangulardentary contact from margin of external mandibular fenestra; (3) dentary with elongate posteroventral process longer than posterodorsal process; (4) posterolateral surface of surangular highly concave (modified from Wu \& Russell [12]).

\section{Type locality}

Taoshuyuanzi, about $30 \mathrm{~km}$ northwest of the Turfan Basin, Xinjiang.

\section{Type horizon}

Vertebrate Fossil Bed IV (kannemeyeriid zone), lower Kelamayi Formation. Middle Triassic: Anisian.

Yonghesuchus sangbiensis Wu, Liu \& Li [13].

\section{Holotype}

IVPP V 12378, incomplete skull with mandible.

\section{Paratype}

IVPP V 12379, incomplete skull in articulation with the first seven cervical vertebrae and several cervical ribs.

\section{Diagnosis}

Characterised by the following autapomorphies: (1) anterior ends of premaxillae tapered to form sharp point together in dorsal view; (2) accessory fossa present within antorbital fossa on dorsal part of ascending process of maxilla; (3) two fossae present on ventral surface of parabasisphenoid between basal tubera and basipterygoid processes; (4) dentary with exceptionally elongate posterodorsal process much longer than posteroventral process (modified from Wu et al. [13]).

\section{Type locality}

North bank of Sangbi Creek, about $1.5 \mathrm{~km}$ southwest of Sangbi Township, Yonghe County, Shanxi province, China.

\section{Type horizon}

Upper part of Member II of the Tongchuan Formation. Late Middle-early Late Triassic: Ladinian-Carnian [31].

\section{Discussion}

Our phylogenetic analysis provides the first support for a gracilisuchid clade, in which we include three previously enigmatic archosauriform species from the Middle Triassic of Argentina and China: Gracilisuchus stipanicicorum, Turfanosuchus dabanensis, and Yonghesuchus sangbiensis. This clade is moderately well supported given that one of its members ( $Y$. sangbiensis) is very incompletely known, and is resolved in a basal position within Suchia. This result provides increased resolution of the previously poorly constrained relationships of early suchians, with increased levels of support for several key early pseudosuchian clades. However, a robust resolution of the phylogenetic position of Gracilisuchidae amongst early suchians will require further work and additional discoveries. Our results contradict previous suggestions that $T$. dabanensis and $Y$. sangbiensis are non-archosaurian archosauriforms, placing both within crown Archosauria (see also Ezcurra et al. [19] and Nesbitt [2] for T. dabanensis).

Within Gracilisuchidae, we find a sister-group relationship between G. stipanicicorum and Y. sangbiensis. We consider this plausible given our reinterpretation of the unusual temporal region of $Y$. sangbiensis as highly similar to that of G. stipanicicorum, and the similar chronostratigraphic position of both taxa relative to the geologically older $T$. dabanensis. Despite this, the sister group relationship is poorly supported, perhaps due to the incomplete nature of the available material of $Y$. sangbiensis. Discoveries of more complete specimens of this taxon will be required in order to achieve a more robust understanding of relationships within Gracilisuchidae.

The oldest crown archosaur body fossils are of poposauroid pseudosuchians, particularly ctenosauriscids, the oldest records of which are clustered around the Early Triassic-Middle Triassic (Olenekian-Anisian) boundary $[2,3,50]$. The Manda beds of Tanzania, supported as late Anisian in age on the basis of terrestrial biochronology, represent the oldest rock unit to yield a diversity of 
crown archosaur clades, including a silesaurid dinosauromorph [51], an erpetosuchid [20], a poposauroid [52], a probable paracrocodylomorph [53], as well as a derived dinosauriform [54] and several undescribed species. The recognition of Gracilisuchidae, whose oldest member ( $T$. dabanensis) is known from the Anisian of China, adds this clade to the roster of crown archosaur groups known from the early Middle Triassic. The occurrence of $T$. dabanensis in western China reinforces the previous evidence based on the distribution of poposauroids that early archosaurs were distributed over much or all of Pangaea from the end of the Early Triassic onwards [3], but may have initially been relatively rare members of faunal assemblages. The high diversity of early archosaur clades recovered from the Manda beds of Tanzania may reflect the late Anisian age of this formation, with the late Anisian potentially marking the point of transition from early Middle Triassic (early Anisian) vertebrate communities with only scarce crown archosaurs to late Middle Triassic (Ladinian) vertebrate communities in which crown archosaurs were diverse and relatively abundant (e.g. the Chañares Formation of Argentina).

During the late Middle Triassic-early Late Triassic (Ladinian-early Carnian), gracilisuchids had a broad distribution (Figure 6), being present in both the Tongchuan Formation of China ( $Y$. sangbiensis) and the Chañares Formation of Argentina (G. stipanicicorum) at approximately similar northern and southern mid-palaeolatitudes (around $40-50^{\circ} \mathrm{N}$ and S). Although this distribution is disjunct, Ladinian and early Carnian terrestrial vertebrate assemblages are scarce worldwide: for example, in China, Y. sangbiensis represents the only specifically diagnosable body fossil material yet described from this time interval. As a result, it is possible that gracilisuchids could have been widespread across Pangaea in the Ladinian and early Carnian, consistent with suggestions of relatively cosmopolitan vertebrate faunas during the Middle Triassic $[55,56]$.

\section{Conclusions}

Based upon new anatomical observations and a revised morphological phylogenetic dataset, we demonstrate the existence of a previously unrecognised clade of early pseudosuchian archosaurs that includes three previously enigmatic archosauriform species from the Middle Triassic of Argentina and China. We term this clade Gracilisuchidae. Our results provide increased resolution of the previously poorly constrained relationships of early archosaurs, with increased levels of phylogenetic support for several key early pseudosuchian clades. Our recognition of Gracilisuchidae provides further support for a rapid phylogenetic diversification of archosaurs by the Middle Triassic. This radiation occurred in the aftermath of the Permo-Triassic mass extinction as part of the broader recovery of post-extinction terrestrial ecosystems. Gracilisuchids occur at approximately similar northern and southern mid-palaeolatitudes (around $40-50^{\circ} \mathrm{N}$ and S).

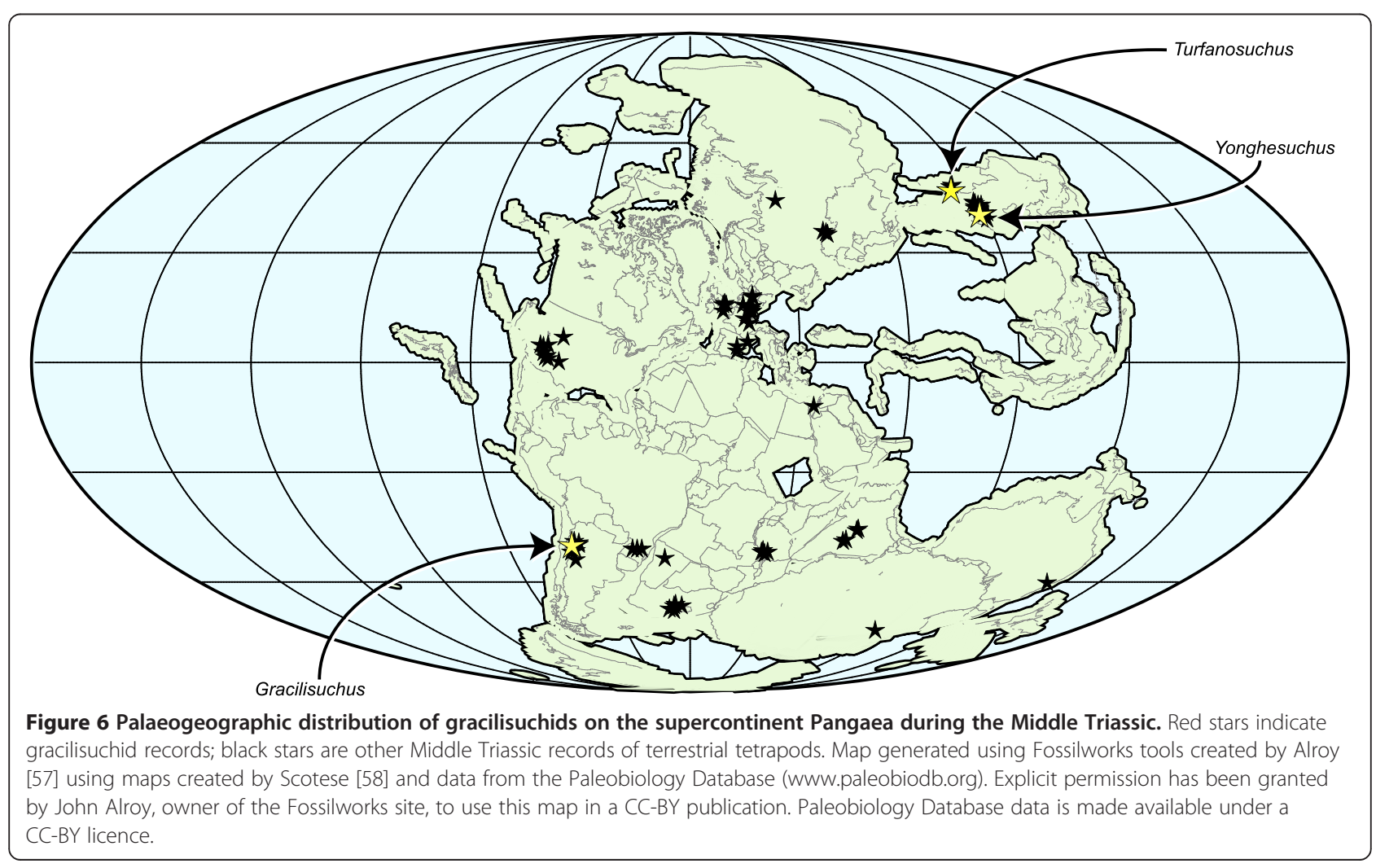


This disjunct distribution demonstrates that early archosaurs were distributed over much or all of Pangaea by the early Middle Triassic although they may have initially been relatively rare members of faunal assemblages.

\section{Availability of supporting data}

The data sets supporting the results of this article are included within the article (and its files).

\section{Additional files}

\section{Additional file 1: Notes on character scorings used in the phylogenetic dataset.}

Additional file 2: Morphological dataset used in main cladistic analysis.

Additional file 3: Morphological dataset used in cladistic analysis incorporating Erpetosuchidae.

Additional file 4: Strict consensus tree for the main cladistic analysis, with nodal values for Bremer support and absolute and GC bootstrap frequencies.

Additional file 5: Strict consensus tree for the cladistic analysis incorporating Erpetosuchidae, with nodal values for Bremer support and absolute and GC bootstrap frequencies.

Additional file 6: Strict consensus tree for the main cladistic analysis when astragalus characters are all coded as uncertain for Turfanosuchus dabanensis, with nodal values for Bremer support and absolute and GC bootstrap frequencies.

Additional file 7: Strict consensus tree for the cladistic analysis incorporating Erpetosuchidae when astragalus characters are all coded as uncertain for Turfanosuchus dabanensis, with nodal values for Bremer support and absolute and GC bootstrap frequencies.

\section{Competing interests}

The authors declare we have no competing interests.

\section{Authors' contributions}

$\mathrm{RJB}, \mathrm{CS}$ and MDE collected anatomical data and carried out phylogenetic analyses. $\lrcorner$ p provided data on geological setting and $J$, AL and RBS provided comparative data on other archosauriforms. RJB, CS and MDE drafted the manuscript, and RJB and MDE prepared the figures. All authors reviewed, edited and approved the final manuscript.

\section{Acknowledgements}

RJB, MDE and RBS are supported by an Emmy Noether Programme Award from the DFG (BU 2587/3-1 to RJB) and a Marie Curie Career Integration Grant (PCIG14-GA-2013-630123 ARCHOSAUR RISE to RJB), and completed this research while at the University of Birmingham. We thank Christian Foth for discussion. We thank M. Belén von Baczko for the photograph used in Figure 1G. Three reviewers and the editor Diego Pol provided helpful comments on an earlier draft of the manuscript.

\section{Author details}

${ }^{1}$ School of Geography, Earth and Environmental Sciences, University of Birmingham, Edgbaston, Birmingham B15 2TT, UK. ${ }^{2}$ Key Laboratory of Vertebrate Evolution and Human Origins of Chinese Academy of Sciences, Institute of Vertebrate Paleontology and Paleoanthropology, Chinese Academy of Sciences, 100044 Beijing, China. ${ }^{3}$ Museo Paleontológico, "Egidio Feruglio", Av. Fontana 140, Trelew, Chubut U9100GYO, Argentina.

Received: 6 February 2014 Accepted: 4 June 2014

Published: 10 June 2014

\section{References}

1. Brusatte SL, Benton MJ, Ruta M, Lloyd GT: Superiority, competition, and opportunism in the evolutionary radiation of dinosaurs. Science 2008, 321:1485-1488.

2. Nesbitt SJ: The early evolution of archosaurs: relationships and the origin of major clades. B Am Mus Nat Hist 2011, 352:1-292.

3. Butler RJ, Brusatte SL, Reich M, Nesbitt SJ, Schoch RR, Hornung JJ: The sail-backed reptile Ctenosauriscus from the latest Early Triassic of Germany and the timing and biogeography of the early archosaur radiation. PLoS One 2011, 6:e25693.

4. Sookias RB, Butler RJ, Benson RBJ: Rise of dinosaurs reveals major body size transitions are driven by passive processes of trait evolution. Proc Roy Soc B-Biol Sci 2012, 279:2180-2187.

5. Chen $Z Q$, Benton MJ: The timing and pattern of biotic recovery following the end-Permian mass extinction. Nat Geosci 2012, 5:375-383.

6. Jetz W, Thomas GH, Joy JB, Hartmann K, Mooers AO: The global diversity of birds in space and time. Nature 2012,491:444-448.

7. Brusatte SL, Benton MJ, Desojo JB, Langer MC: The higher-level phylogeny of Archosauria. J Syst Palaeontol 2010, 8:3-47.

8. Romer AS: The Chañares (Argentina) Triassic reptile fauna. XIII. An early ornithosuchid pseudosuchian, Gracilisuchus stipanicicorum, gen. et sp. nov. Breviora 1972, 389:1-24.

9. Lecuona A, Desojo JB: Hind limb osteology of Gracilisuchus stipanicicorum (Archosauria: Pseudosuchia). Earth Env Sci TR So 2011, 102:105-128.

10. Lecuona A: Anatomía y relaciones filogenéticas de Gracilisuchus stipanicicorum y sus implicancias en el origen de Crocodylomorpha, PhD thesis. Universidad de Buenos Aires: Facultad de Ciencias Exactas y Naturales; 2013.

11. Young CC: On a new pseudosuchian from Turfan, Sinkiang. Mem Inst Vert Paleontol Paleoanthropol B 1973, 10:15-37.

12. Wu X-C, Russell AP: Redescription of Turfanosuchus dabanensis (Archosauriformes) and new information on its phylogenetic relationships. J Vertebr Paleontol 2001, 21:40-50.

13. Wu X-C, Liu J, Li J-L: The anatomy of the first archosauriform (Diapsida) from the terrestrial Upper Triassic of China. Vert PalAs 2001, 39:251-265.

14. Benton MJ: Origin and relationships of Dinosauria. In The Dinosauria. 2nd edition. Edited by Weishampel DB, Dodson P, Osmólska H. Berkeley: University of California Press; 2004:7-19.

15. Parrish JM: Phylogeny of the Crocodylotarsi, with reference to archosaurian and crurotarsan monophyly. J Vertebr Paleontol 1993, 13:287-308.

16. Juul L: The phylogeny of basal archosaurs. Palaeont afr 1994, 31:1-38.

17. Benton MJ, Walker AD: Erpetosuchus, a crocodile-like basal archosaur from the Late Triassic of Elgin, Scotland. Zool J Linn Soc-Lond 2002, 136:25-47.

18. Dilkes DW, Sues H-D: Redescription and phylogenetic relationships of Doswellia kaltenbachi (Diapsida: Archosauriformes) from the Upper Triassic of Virginia. J Vertebr Paleontol 2009, 29:58-79.

19. Ezcurra MD, Lecuona A, Martinelli A: A new basal archosauriform diapsid from the Lower Triassic of Argentina. J Vertebr Paleontol 2010, 30:1433-1450.

20. Nesbitt SJ, Butler RJ: Redescription of the archosaur Parringtonia gracilis from the Middle Triassic Manda Beds of Tanzania, and the antiquity of Erpetosuchidae. Geol Mag 2013, 150:225-238.

21. Goloboff $P$, Farris J, Nixon K: TNT: a free program for phylogenetic analysis. Cladistics 2008, 24:774-786.

22. Coddington J, Scharff N: Problems with zero-length branches. Cladistics 1994, 10:415-423.

23. Swofford DL: PAUP*. Phylogenetic analysis using parsimony (*and other methods). Version 4. Sunderland: Sinauer Associates; 1998.

24. Desojo JB, Ezcurra MD, Schultz CL: An unusual new archosauriform from the Middle-Late Triassic of southern Brazil and the monophyly of Doswelliidae. Zool J Linn Soc-Lond 2011, 161:839-871.

25. Irmis R, Mundil R, Marsicano C, Mancuso A: U-Pb dating of redeposited volcanics in non-marine sedimentary strata: case studies from the early Mesozoic [abstract], Program and Abstracts, 73rd Annual Meeting, Society of Vertebrate Paleontology; 2013:147.

26. Fröbisch J: Composition and similarity of global anomodont-bearing tetrapod faunas. Earth-Sci Rev 2009, 95:119-157.

27. Wu X: Two pseudosuchian reptiles from Shan-Gan-Ning basin. Vert PalAs 1982, 20:291-301.

28. Gower DJ, Sennikov AG: Early archosaurs from Russia. In The age of dinosaurs in Russia and Mongolia. Edited by Benton MJ, Shishkin MA, Unwin DM, Kurochkin EN. Cambridge: Cambridge University Press; 2000:140-159. 
29. Sookias RB, Butler RJ: Euparkeriidae. Geol Soc London Spec Publ 2013, 379:35-48.

30. Schoch RR: Osteology of the small archosaur Aetosaurus from the Upper Triassic of Germany. Neues Jahrb Geol P-A 2007, 246:1-35.

31. Liu J, Li L, Li X-W: SHRIMP U-Pb zircon dating of the Triassic Ermaying and Tongchuan formations in Shanxi, China and its stratigraphic implications. Vert PalAs 2013, 51:162-168.

32. Sereno PC, Martínez RN, Alcober OA: Osteology of Eoraptor lunensis (Dinosauria: Sauropodomorpha). J Vertebr Paleontol 2013, 32(Suppl 6):83-179.

33. Martínez RN, Sereno PC, Alcober OA, Colombi CE, Renne RR, Montañez IP, Currie BS: A basal dinosaur from the dawn of the dinosaur era in southwestern Pangaea. Science 2011, 331:206-210.

34. Walker AD: Triassic reptiles from the Elgin area: Ornithosuchus and the origin of carnosaurs. Philos T R Soc B 1964, 248:53-134.

35. Cope ED: Synopsis of the extinct Batrachia, Reptilia and Aves of North America. Trans Am Phil Soc 1869, 14:1-252.

36. Sereno PC: Stem Archosauria, Taxonsearch website. 2005. Available: http:// taxonsearch.org/Archive/stem-archosauria-1.0.php.

37. von Zittel KA: Handbuch der Palaeontologie. 1. Abteilung: Palaeozoologie. III. München: R. Oldenbourg; 1887

38. Krebs B: Die Archosaurier. Naturwissenschaften 1974, 61:17-24.

39. Huxley $\mathrm{TH}$ : The crocodilian remains found in the Elgin sandstones, with remarks on the ichnites of Cummingstone. Mem Geol Surv UK Monograph 1877, 3:1-51.

40. Fraas O: Aëtosaurus ferratus Fr. Die gepanzerte Vogel-Esche aus dem Stubensandstein bei Stuttgart. Württembergische naturwissenschaftliche Jahreshefte 1877, 33:1-22.

41. Mehl MG: Poposaurus gracilis, a new reptile from the Triassic of Wyoming. J Geol 1915, 23:516-522.

42. Chatterjee S: Postosuchus, a new thecodontian reptile from the Triassic of Texas and the origin of tyrannosaurs. Philos T R Soc B 1985, 309:395-460.

43. Emmons E: Geological report of the midland counties of North Carolina. New York: G.P. Putnam; 1856.

44. Newton ET: Reptiles from the Elgin sandstone - description of two new genera. Philos T R Soc B 1894, 185:573-607.

45. Hunt AP: A new ornithischian dinosaur from the Bull Canyon Formation (Upper Triassic) of east-central New Mexico. In Dawn of the age of dinosaurs in the American Southwest. Edited by Lucas SG, Hunt AP. Albuquerque: New Mexico Museum of Natural History; 1989:355-358.

46. Laurenti JN: Specimen medicum, exhibens synopsin reptilium emendatam cum experimentis circa venena et antidota reptilium austriacorum. Vienna: J.T.N. de Trattnern; 1768

47. Linnaeus C: Systema naturae per regna tria naturae. Vol. 1. Regnum animale. 10th edition. Stockholm: Laurentii Salvii; 1758.

48. Carroll RL: Vertebrate Paleontology and Evolution. New York: W.H. Freeman and Company; 1988

49. Langer MC, Nesbitt SJ, Bittencourt JS, Irmis RB: Non-dinosaurian Dinosauromorpha. In Anatomy, Phylogeny and Palaeobiology of Early Archosaurs and their Kin, Volume 379. Edited by Nesbitt SJ, Desojo JB, Irmis RB. London: Geological Society Special Publications; 2013:353-392.

50. Nesbitt SJ, Liu J, Li C: The oldest archosaur: A sail-backed suchian from the Heshanggou Formation (Early Triassic: Olenekian) of China. Earth Env Sci T R So 2011, 101:271-284

51. Nesbitt SJ, Sidor CA, Irmis RB, Angielczyk KD, Smith RMH, Tsuji LA: Ecologically distinct dinosaurian sister-group shows early diversification of Ornithodira. Nature 2010, 464:95-98.

52. Butler RJ, Barrett PM, Abel RL, Gower DJ: A possible ctenosauriscid archosaur from the Middle Triassic Manda Beds of Tanzania. J Vertebr Paleontol 2009, 29:1022-1031.

53. Lautenschlager S, Desojo JB: Reassessment of the Middle Triassic rauisuchian archosaurs Ticinosuchus ferox and Stagonosuchus nyassicus. Paläontol Zeit 2011, 85:357-381.

54. Nesbitt SJ, Barrett PM, Werning S, Sidor CA, Charig AJ: The oldest dinosaur? A Middle Triassic dinosauriform from Tanzania. Biol Lett 2012, 9:20120949.

55. Shubin NH, Sues H-D: Biogeography of early Mesozoic continental tetrapods: patterns and implications. Paleobiology 1991, 17:214-230.
56. Ezcurra MD: Biogeography of Triassic tetrapods: evidence for provincialism and driven sympatric cladogenesis in the early evolution of modern tetrapod lineages. Proc Roy Soc B-Bio/ Sci 2010, 277:2547-2552.

57. Alroy J: Online paleogeographic map generator. http://fossilworks.org/cgi-bin/ bridge.pl?a=mapForm.

58. Scotese CR: Atlas of Earth History, Volume 1, Paleogeography. Arlington, Texas: PALEOMAP Project; 2001

doi:10.1186/1471-2148-14-128

Cite this article as: Butler et al:: New clade of enigmatic early archosaurs yields insights into early pseudosuchian phylogeny and the biogeography of the archosaur radiation. BMC Evolutionary Biology 2014 14:128.

\section{Submit your next manuscript to BioMed Central and take full advantage of:}

- Convenient online submission

- Thorough peer review

- No space constraints or color figure charges

- Immediate publication on acceptance

- Inclusion in PubMed, CAS, Scopus and Google Scholar

- Research which is freely available for redistribution

Submit your manuscript at www.biomedcentral.com/submit
C Biomed Central 